\title{
8 PRIVACY CONSIDERATIONS IN LOCATION-BASED ADVERTISING
}

\author{
Heng Xu \\ Hock-Hai Teo \\ Department of Information Systems \\ National University of Singapore \\ Singapore
}

\begin{abstract}
The emergence of mobile communication and positioning technologies has presented advertisers and marketers with a new type of advertising approach: location-based advertising (LBA). Advertisers could deliver contextually appropriate advertising messages through wireless devices on a geographically targeted basis and could reach mobile consumers when they are most likely to make a purchase (Kölmel and Alexakis 2002). However, because $L B A$ could also associate the lifestyle habits, behaviors, and movements with a consumer's personal identity, privacy concern is particularly salient for LBA. Drawing on the privacy literature and the exchange theory, we employ an experimental approach to develop and test an adoption model by including risk-benefit analysis as the major antecedent to behavioral intention. Two environmental variables-industry privacy self-regulation and privacy legislation-are included to further assess the role of industry self-regulator versus government legislator in bearing the responsibility of assuring consumer privacy. Our findings extend individual adoption research into the new L-Commerce context and offer several important implications for various players in the LBA industry: wireless advertising service/content providers, merchants, privacy advocates and government legislators.
\end{abstract}

Keywords Mobile commerce, location-based advertising (LBA), information privacy

\section{INTRODUCTION}

The emergence of mobile communication and positioning technologies has presented new opportunities and challenges to transform electronic commerce applications 
for the mobile arena. Spurred by developments in global positioning system (GPS) and sophisticated cellular triangulation techniques, telecommunication operators together with merchants are offering consumers pervasive flexibility to be uniquely reachable and to access networks and services while on the move. These commercial locationsensitive applications and value-added services that utilize geographical positioning information to provide value-added services are termed location-based services (LBS), and are generally marketed under "L-Commerce" (Gidari 2000).

The fast-growing mobile and Internet markets are powering the L-Commerce market evolution. With the advent of sophisticated positioning technologies and the widespread availability of accurate outdoor location information, advertisers and marketers are now presented with a new type of advertising approach: location-based advertising (LBA). With LBA, advertisers could deliver contextually appropriate advertising messages through the wireless devices on a geographically targeted basis and could reach mobile consumers when they are most likely to make a purchase (Kölmel and Alexakis 2002). Wireless devices have become a new medium through which advertisements, promotions, coupons, and other offers that are uniquely customized to an individual's tastes, geographical location, and the time of day are offered. Analysts predict that LBA messages are expected to create 5 to 10 times higher clickthrough rates compared to the Internet advertising messages (Ververidis and Polyzos 2002).

LBA could take the form of pull-based (users request the advertising content based on their locations) or push-based (location-sensitive content is automatically sent to users based on their locations) (Kölmel and Alexakis 2002). While LBA has the potential to benefit both merchants and consumers, its acceptance rate among consumers is still relatively low. One of the primary reasons is the consumers' fears of privacy invasion, especially for push-based LBA as consumers are wary of being tracked whenever and wherever they are, or being spammed with mobile advertisements (Barwise and Strong 2002). Improper handling of location information would result in the discovery and matching of location data and identity to classify consumers, thereby enhancing the visibility of their behavior, and increasing the scope for potentially personally embarrassing situations (Beinat 2001). Indeed, there is a growing call for "No LCommerce without L-Privacy" by privacy advocates and consumers (Gidari 2000).

Given that this stance could stymie the development of push-based LBA (Beinat 2001), it is imperative that we develop a complete understanding of the role that privacy, plays in influencing a consumer's evaluation and adoption of push-based LBA. Drawing on the exchange theory, privacy and advertising literature, we aim to predict a consumer's usage intention toward push-based LBA from a privacy lens. Additionally, we seek to understand how merchants and policy makers could also shape the privacy risk perceived by the consumer in the context of adopting push-based LBA. We test our model using one push-based LBA ${ }^{1}$ application- mobile coupon (M-Coupon) service-through an experimental approach. This study is novel to the extent that we have yet to find any empirical study that looks at these intertwined issues in the LBA

'From this point onward, we use the term $L B A$ to mean push-based LBA. Our study focuses only on push-based LBA. 
context. The marriage of the advertising, privacy, organizational justice, and legal literature streams may provide a deeper understanding of the issues affecting LBA evaluation and adoption, and therefore inform adoption research in the Information Systems discipline. Our findings can potentially be useful to privacy advocates, regulatory bodies and merchants to help shape or justify their decisions concerning LCommerce.

\section{THEORETICAL BACKGROUND AND RESEARCH HYPOTHESES}

Figure 1 presents our research model. In this study, we adopt a narrow focus in examining the role of privacy in predicting adoption intention. Based on privacy literature, privacy concern is conceptualized as a risk-benefit analysis, which is the basic structure of our model. According to the theory of procedural justice and deterrence theory, we further hypothesize that industry privacy self-regulation and privacy legislation may affect a consumer's privacy risk perception of location information disclosure. ${ }^{2}$ Drawing on the advertising literature, we posit that the informativeness and the entertainment value of a LBA message could help shape the perceived benefits of location information disclosure. The following sections develop and elaborate the key constructs and the theoretical rationale for the causal relationships among the constructs in the research model.

\subsection{The Role of Privacy Concern in Intention to Use LBA}

Information privacy has been generally defined as the ability of the individual to control the terms under which personal information is acquired and used (Westin 1967). Prior research has repeatedly shown information privacy is an utmost concern in diverse organizational and marketing contexts and it is argued that information privacy continues to be eroded as a result of technology innovations (Stone and Stone 1990). One of the key findings within extant privacy studies is that privacy is not absolute and there will be occasions on which privacy can be interpreted in "economic (cost/benefit) terms" (Klopfer and Rubenstein 1977). It was further suggested that individuals should be willing to disclose personal information in exchange for some economic or social benefits subject to an assessment that their personal information will subsequently be used fairly and that they will not suffer negative consequences in the future (Laufer and

${ }^{2}$ In this paper, "location information disclosure" refers to all the information disclosed for the purpose of using LBA, including both the dynamic location data and the static personal data such as identity, shopping preferences, mobile phone number, and others. It is the combination of both these groups of data that enhances the visibility of the individual behavior and thus poses a serious threat to individual privacy. 


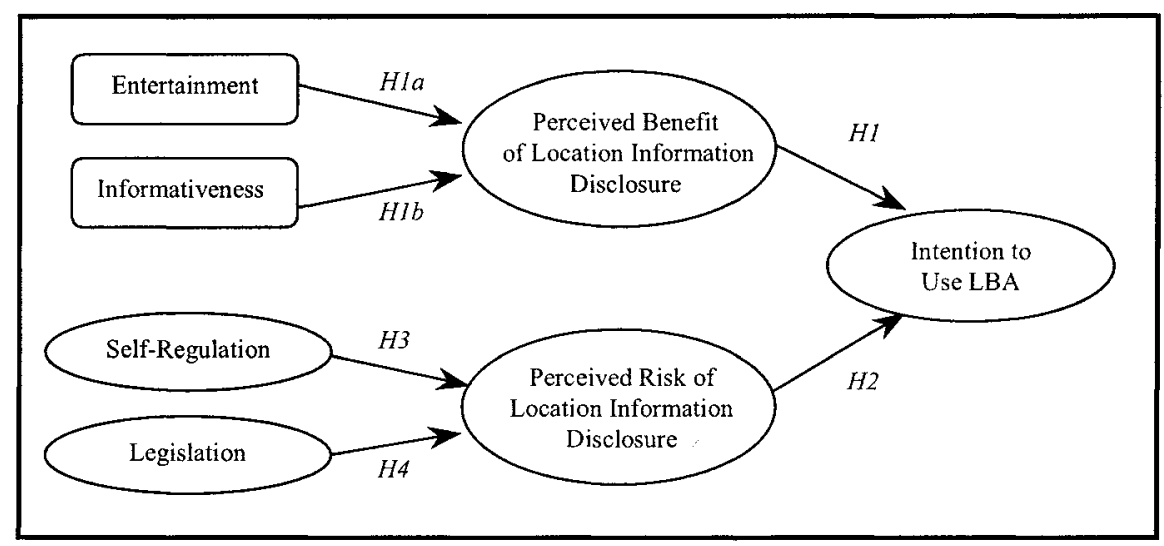

Figure 1. Research Model

Wolfe 1977). Similarly, consumers are likely to behave as if they are performing a privacy calculus in assessing the outcomes they receive as a result of providing personal information to corporations (Culnan 1995).

One theoretical perspective that may help predict a consumer's privacy preference is the exchange theory (Bagozzi 1975; Houston and Gassenheimer 1987). This theory characterizes three classes of meanings of exchange: utilitarian, symbolic or mixed (Bagozzi 1975). A utilitarian exchange is an interaction whereby goods are given in return for money or other goods (Bagozzi 1975, p. 36) and it is considered as the first exchange (Culnan and Bies 2003, p.326). The concept of second exchange is proposed to explain the privacy calculus phenomenon and refers to the exchange whereby the consumer's personal information is given in return for value such as higher quality service and personalized offers or discounts (Culnan and Bies 2003). Applying the second exchange framework to LBA usage behavior, we can treat the usage of LBA as an exchange where consumers disclose their location information in return for the proper value (e.g., timely personalized discount information based on the consumers' location) provided by the firm. Hence, we predict that mobile consumers should be willing to disclose personal information in exchange for proper value provided by LBA services as long as they perceive that benefits exceed the current or future risks of using LBA. Hence, we hypothesize

H1: Higher perceived benefits of location information disclosure will lead to greater intent to use $L B A$.

H2: Higher perceived risks of location information disclosure will lead to lower intent to use $L B A$. 


\subsection{Components of Perceived Benefits: Entertainment and Informativeness}

Perceived benefits of location information disclosure are gained only when LBA is utilized. According to previous advertising research, consumers mainly value advertising media for the entertainment and informational value (Chen and Wells 1999; Ducoffe 1996; Eighmey 1997; Eighmey and McCord 1998). Entertainment refers to the extent to which the advertising media is fun and entertaining to media users (Eighmey 1997; Eighmey and McCord 1998) and the value of media entertainment lies in its ability to fulfill users' needs for escapism, hedonistic pleasure, aesthetic enjoyment, or emotional release (McQuail 1983). Prior research suggests that providing higher entertainment value is likely to motivate them to use the media more often (Eighmey 1997; Eighmey and McCord 1998). Hence, a corollary to $\mathrm{Hl}$ would be

\section{H1a: Higher level of entertainment will lead to greater intent to use LBA.}

Informativeness is defined as the extent to which the advertising media provides users with resourceful and helpful information (Chen and Wells 1999; Ducoffe 1996). Past studies have suggested that media users consider advertisers' ability to provide audience information as the fundamental reason for accepting the ad itself (Bauer and Greyser 1968). Also, it was indicated that advertising's informational role is its major legitimizing function (Rotzoll et al. 1986). By matching the information on personal preferences provided by consumers with their current location information, LBA is able to provide consumers with personalized and localized up-to-date advertising messages. The increased relevance and timeliness of an advertising message will assist consumers in making a better purchase decision and consequently perceiving LBA to be valuable. Hence, a corollary to $\mathrm{H} 1 \mathrm{would}$ be

H1b: Higher level of informativeness will lead to greater intent to use LBA.

\subsection{Mitigating Consumer's Privacy Risk Perception: Fair Information Practices}

Fair information practices (FIPs), a general term for a set of global principles, has been developed to balance consumer's privacy concerns with a firm's need to use personal information. FIPs regulate the disclosure and subsequent use of personal information by empowering individuals with control over their information as well as giving them an assurance that firms will adhere to a set of principles that most consumers find acceptable (Culnan and Armstrong 1999). Businesses adhering to FIPs can lower the privacy concerns associated with the disclosure of personal information through assuring consumers that the firm will abide by a set of rules (Greenberg 1987) and will not behave opportunistically (Shapiro 1987). However, there is still an ongoing debate on the relative effectiveness of legislation and industry self-regulation in insuring that a firm's implementation of FIPs is available, accurate, and understandable, and that 
consumers have legitimate choices about how their personal information is subsequently used (e.g., Caudill and Murphy 2000; Culnan and Bies 2003). In response to this debate, we draw on the procedural justice and deterrence theories to provide the theoretical bases for analyzing the relative effectiveness of two different regulatory approaches to the FIPs implementation-industry self-regulation approach and legislation approach -in assuaging consumers' privacy concerns.

\subsubsection{Industry Self-Regulation on FIPs Implementation: Procedural Justice Perspective}

Culnan and Bies (2003) proposed that a justice theoretical perspective provides a useful framework for analyzing consumers' privacy perceptions. Of particular relevance to industry privacy self-regulation is the procedural justice perspective (e.g., Lind and Tyler 1988). Procedural justice refers to the perception by individuals that a particular activity in which they are participants is conducted fairly and how those procedures are enacted (Lind and Tyler 1988). Research has shown that even if outcomes are not favorable to individuals, they are less likely to be dissatisfied with unfavorable outcomes if they believe that the procedures used to bring about those outcomes are fair (Greenberg 1987; Lind and Tyler 1988).

The self-regulation approach to implementing FIPs is one way to enhance consumers' perceptions of procedural justice, because self-regulation provides individuals with control over the disclosure and subsequent use of their personal information via announced privacy policies or privacy seals from trusted third parties (such as TRUSTe, BBBOnline, and Online Privacy Alliance) or other industry association (e.g., Direct Marketing Association). Third party intervention has been employed in self-regulation to provide legitimacy and trustworthiness to companies through seals of approval that are designed to verify adequate privacy compliance. These efforts specifically address FIPs with participating firms agreeing to provide notice, choice, access, security, and enforcement. Previous studies have shown that businesses that conform to the industry self-regulation practices instill greater confidence in consumers to reveal their personal information and thereby lower consumers' privacy risk perceptions (Caudill and Murphy 2000). Hence, we hypothesize

H3: The presence of industry self-regulation on location information protection should lead to lower perceived risk of using $L B A$.

\subsubsection{Legislation on FIPs Implementation: Deterrence Theory Perspective}

Privacy studies suggest that legislation could have a major positive impact on privacy perceptions (Culnan 2000) since the legal system is the most powerful mechanism for the exercise of social control (Spiro and Houghteling 1981). Legal language is powerful because it is oriented toward specific (correlative) rights and duties (Spiro and Houghteling 1981). A general civil right of individual integrity, expressed 
through various doctrines of tort, property and contract law, protects an individual's freedom of action, ownership and decision from certain kinds of interference by others. Deterrence theory (e.g., Gibbs 1986; Tittle 1980) shows that the legal system requires that offenders be punished in order to maintain the deterrent effectiveness of the system. In essence, illegal behavior can be deterred through the threat of punishment (Tittle 1980).

Deterrence theory has a direct bearing on privacy invasion issues. Recognizing the deterrent effectiveness of a legal system, consumers may perceive a lower level of privacy invasion risks involved in using LBA. Evidence from privacy studies in the Internet usage provides support for the effects of legislation on users' perceptions of privacy protection. The majority, 58 percent, of the American public wants the government to pass laws to protect privacy and 24 percent says that the government should formally recommend privacy standards (Rotenberg 1998). In the LBA context, legislation on location data protection should play an important and direct role in lowering the privacy risk perceptions of using LBA. Hence, we hypothesize

\section{H4: The presence oflegislation on location information protection should lead to lower perceived risk of using $L B A$.}

\subsection{Control Variables Influencing LBA Adoption}

Prior research on information privacy and IT adoption suggests a number of additional factors should be included as control variables because of their potential influence on perceived benefit, perceived risk, and intention to use LBA. They are: prior experience of using mobile applications (Culnan 1995), previous privacy experience (Smith et al. 1996; Stone and Stone 1990), and innovativeness (Joseph and Shailesh 1984; Pedersen 2005).

\section{RESEARCH METHOD}

A laboratory experiment was used to test the proposed model because of its ability to support the testing of causal relationships between manipulated and theoretical constructs with minimal interference from extraneous variables. At present, most of the available mobile applications are delivered to users over different underlying technology platforms such as WAP-based (wireless application protocol) or GPRS-based (general packet radio service) mobile Internet and short messaging service (SMS) (Xu et al. 2003). Since most mobile phones support the SMS functionality, LBA in our study was introduced as the service offered to mobile phone users via SMS based on the cellidentification (cell-ID) ${ }^{3}$ technique employed by the network of telecom operators.

${ }^{3}$ Cell-ID, or cell of origin (COO), works by identifying the cell of the network in which the handset is operating (Barnes 2003). Such technique is the main technology that is widely deployed in mobile communication networks today. It requires no modification to handsets or 
One specific LBA application-the mobile coupon (M-coupon) service-is utilized as the scenario in the experiment. The M-coupon service involves recruiting consumers by service registration and interest subscription: consumers can register their mobile phone numbers and subscribe to a list of merchants who provide M-coupon services, based on their interests and preferred period of time for receiving $\mathrm{M}$-coupons. Profiling information is then used to target the subscribers and their mobile phones will be sent related advertisements when they appear within the vicinity of the merchants.

\subsection{The Experiment}

The study was designed as a 2 (with/without self-regulation) $\times 2$ (with/without legislation) factorial experiment design. Participants were randomly assigned to one of the four groups. The gender ratio of each group was kept to $1: 1$; other individual characteristics and personality factors were controlled by randomization.

A total of 84 undergraduate students in the School of Computing at a large university in Singapore were recruited via an online registration system, and participated in the experiment ( 42 females, 42 males). They were required to complete an online registration by providing their background information. All of the subjects own mobile phones. As an incentive for participation, each subject received $S \$ 15$ upon completion. ${ }^{4}$ While the use of undergraduate students as potential LBA users might limit the generalizability of the results, we believe that this should not be a major concern because research indicates that younger individuals are among the most avid users of mobile technologies (Pedersen 2005) and, arguably, represent the next generation of mobile consumers.

All subjects began the experiment by answering questions about their personal information as a form of control check. The subjects were then asked to assume the role of a potential LBA user and were presented with the scenario of M-coupon service which was described in the form of a real company Web site to ensure realism (see Appendix $\mathrm{F}$ for a detailed description). Next, they were asked to complete a questionnaire regarding their perceptions of benefits and risks, and their intention to use LBA.

Two exogenous variables -self-regulation (SREG) and legislation (LEGI) -were manipulated to create the environment in which the potential LBA users have to make their choices. Self-regulation was manipulated by providing a TRUSTe seal and a privacy policy statement on the service provider's Web site. Legislation was manipulated by informing the subjects that L-Commerce transactions are governed by related location privacy protection laws. A summary report containing the gist of the Location Privacy Protection Act was provided to those subjects belonging to the legislation treat-

networks since it uses the mobile network base station as the location of the caller (Barnes 2003). However, although locating the caller through this technique is fast (i.e., typically around three seconds), accuracy is relatively low (in the range of 200 meters), depending on cell size (Giaglis et al. 2002). Generally speaking, the accuracy is higher in densely covered areas (for example, urban places) and much lower in rural environments (Zeimpekis et al. 2003).

${ }^{4}$ The reward was framed in Singapore dollars. As of January 2005, one Singapore dollar is about 60 U.S. cents. 
ment group. The Location Privacy Protection Act used in the experiment was modified from a proposal by the Senate and House of Representatives of the United States of America. ${ }^{5}$ The language used in the Act was localized to suit Singapore's context. During the experiment, no one questioned the authenticity of the Act; however, upon completion of all the experimental treatments, the experiment administrators informed the subjects in the legislation treatments that there was no such legislation in Singapore.

The Web-based system used for this study was programmed to ensure that each subject viewed the treatment conditions before they were allowed to proceed, and that subjects answered all questions before leaving the experiment. These features allowed us to ensure that the subjects had actually read the manipulated conditions completely before they gave their responses to questions asking them about entertainment, informativeness, perceived risk, and intended use.

\subsection{Measures}

As far as possible, constructs were adapted from existing measurement scales used in prior studies in advertising, consumer behavior, and information privacy to fit the LBA context where necessary. Intent to use and perceived risk were operationalized as reflective constructs, while perceived benefit was operationalized as a formative construct formed from two subconstructs: entertainment and informativeness. The instrument was further validated by assessing the measurement model using confirmatory factor analyses (LISREL 8.51). Appendix C presents the questions measuring each construct in this study.

\section{DATA ANALYSIS AND RESULTS}

\subsection{Manipulation Check}

The manipulations on self-regulation and legislation were checked against true/false questions administered after the experiment. All subjects responded correctly on these questions, suggesting that the subjects have perceived the experiment in the way intended. Additional questions were also posed to assess the level of understanding of the privacy statements and related laws for those subjects belonging to the selfregulation and legislation treatment groups. The subjects' responses to those questions measuring self-regulation $(t=16.88, p<.001)$ and legislation $(t=10.26, p<.001)$ are all significantly different from the neutral value of four.

${ }^{5}$ The details of the proposal are available at http://www.techlawjournal.com/congl07/ privacy/location/s1164is.asp. 


\subsection{Analysis Strategy}

Structural equation modeling (SEM) was adopted for data analyses. Following the approach adopted by Teo, Wei and Benbasat (2003), we used both linear structural relations modeling (LISREL) and partial least squares (PLS) for data analysis. LISREL is used to perform confirmatory factor analysis of the measurement items used to capture the dimensions of the subconstructs. Using LISREL for confirmatory factor analyses provides a more rigorous assessment of the fit between the collected data and the theoretical factor structure, and satisfies the minimum requirements of assessing the measurement properties of unidimensionality, convergent validity, and discriminant validity (Bagozzi 1980). PLS is used for hypotheses testing primarily because it follows a component-based strategy and thus does not depend on having multivariate normal distributions, interval scales, or a large sample size (Fornell and Bookstein 1982). PLS is generally more appropriate for testing theories in the early stages of development (Fornell and Bookstein 1982). Given the nature of exploratory study and the use of formative construct (i.e., perceived benefit) in our study, PLS is the preferred technique for testing the structural model. Appendices A and B show the descriptive statistics and the intercorrelations of the study variables respectively.

\subsection{Evaluating the Measurement Model}

Four multiple-items constructs - entertainment, informativeness, perceived risk, and intent to use - are subjected to confirmatory factor analyses using LISREL 8.51. The validity of the constructs is assessed in terms of unidimensionality, convergent validity, internal consistency and discriminant validity.

Unidimensionality and convergent validity ensure that all the items measure a single underlying construct (Bagozzi and Fornell 1982). Following an iterative procedure of changing one item in each step and the modification indices provided by LISREL (Jöreskog 1993), refinements to this model are made by eliminating two items of the informativeness construct with low loading or high cross loading. The final model comprising 16 items shows some improvement (see Appendices C and D). As is evident, all except two indicator loadings are above the criterion of 0.707 and significant (Hair et al. 1998). The errant indicators, INF2 and INT3, which have no cross-loading problems, are significant, and do not contribute to the problems of convergent validity and internal consistency, are retained. The model fit indices (Appendix D) also provide evidence of the unidimensionality of the items. Except the standardized RMR index, all indices were close to or above the criterion levels.

The internal consistency of each dimension is assessed by computing Cronbach's alpha, composite reliability, and the average variance extracted (Hair et al. 1998). Appendix $C$ presents the results along these dimensions. Cronbach's alpha and the composite reliabilities both exceed Nunnally's (1978) criterion of 0.70 while the average variances extracted for the constructs are all above 50 percent (Hair et al. 1998).

Discriminant validity reflects the extent to which the measures for each construct are distinctly different from each other, and is generally assessed by testing whether the correlations between pairs of constructs are significantly different from unity (Anderson 
1987). For each pair of constructs, the correlation between a referent construct and another construct is unconstrained in one model but is set to unity in another model. Constraining the correlation between pairs of constructs to unity suggests that all of the items measure the same construct. Discriminant validity is established if the $\chi^{2}$ value of the unconstrained model is significantly lower than that of the constrained model. Appendix E shows strong evidence of discriminant validity.

\subsection{Evaluating the Structural Model}

With adequacy in the measurement models affirmed, PLS is used to assess the structural model. Hypotheses and corollaries testing are performed by examining the sign, the significance of the path coefficients, the weights of the dimensions of the constructs and the explanatory power of the structural model, respectively. A bootstrapping technique is applied to estimate the significance of the path coefficients and the weights of the dimensions of constructs. Since PLS does not generate any overall goodness of fit index, predictive validity is assessed primarily with the examination of the explanatory power and significance of the hypothesized paths. The explanatory power of the structural model is assessed based on the amount of variance in the endogenous construct (intent to use LBA) for which the model could account. All statistical tests are assessed at a 5 percent level of significance using one-tailed t-tests because our hypotheses and corollaries were unidirectional in nature.

Figure 2 depicts the structural model. Our structural model could explain 23.8 percent of the variance for the intention to use LBA. Each hypothesis $(H l$ to $H 4)$ corresponds to a path in the structural model. Perceived benefit $(H 1)$ and perceived risk of location information disclosure $(H 2)$ were significant predictors of the intention to use

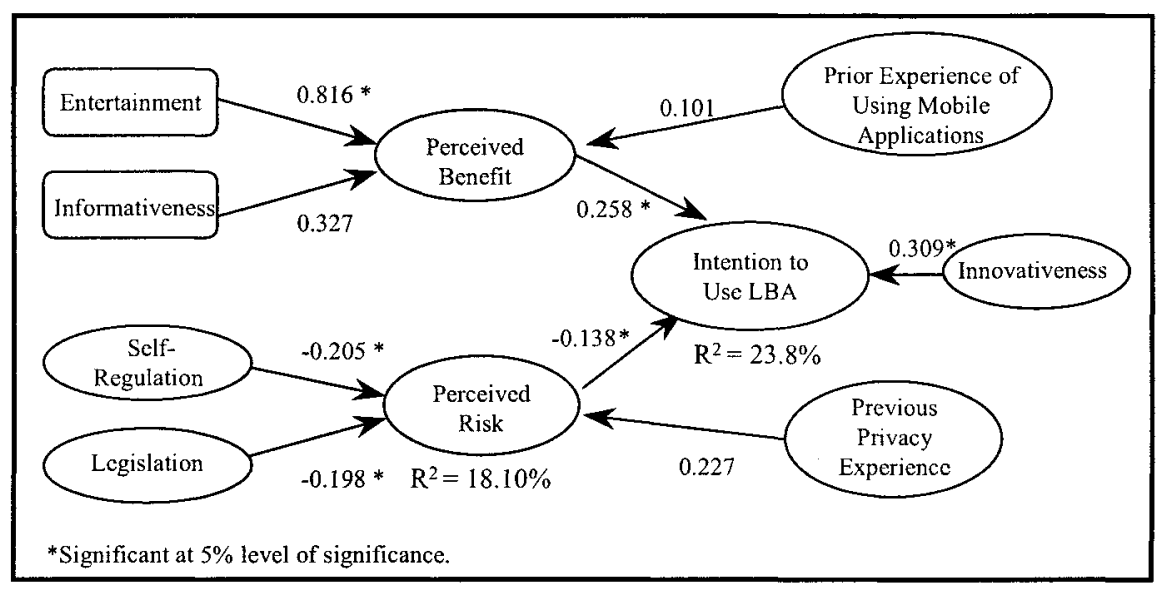

Figure 2. Results of PLS Analyses for Theoretical Model 
LBA; and self-regulation (H3) and legislation (H4) were significant predictors of perceived risk. However, regarding the two corollaries to Hl, Hla was supported but $H l b$ was not supported.

\section{DISCUSSION AND CONCLUSIONS}

This study set out to integrate fragmented theories and research on advertising, privacy, organizational justice, and legal literature streams into a unique adoption model that captures the main inhibiting influences in the new L-Commerce context. Consistent with previous studies (Culnan 1995; Culnan and Bies 2003), the evidence from this study indicates that consumers are rational and are willing to disclose their location information in exchange for some benefits subject to the second exchange in LBA context. Our proposed model is able to account for 23.8 percent of the variances in usage intention, which possesses enough explanatory power to make interpretation of path coefficients meaningful. Thus, risk-benefit analysis underpinned by the exchange theory, is shown to be a major antecedent of usage intention in LBA. Furthermore, our findings help provide some initial insights into the controversial issues surrounding the role of industry self-regulation and legislation in assuring consumer privacy. In particular, our results showed that consumers did regard self-regulation and legislation on location information protection as the important factors affecting privacy concern in LBA. Therefore, both procedural justice theory and deterrence theory appear to be suitable theories for identifying the critical factors that have influence on the perceived risk of location information disclosure.

Among the two factors that were hypothesized to form benefit perception, entertainment contributed predominantly to benefit perception. This suggests that consumers could be more likely to use LBA if the advertising messages are perceived to be fun and entertaining. In contrast, informativeness did not contribute significantly to the formation of benefit perception. Two explanations arising from the limitations of this study are plausible. First, our sample population of university students may have placed a higher premium on fun and entertainment when using LBA compared to general mobile users. Second, our laboratory experiment might not be able to fully operationalize the informativeness factor in terms of relevance and timeliness since the subjects were not in a real shopping scenario and they were not actually on the move. Hence, some caution must be exercised when generalizing these findings.

Notwithstanding these limitations, we believe our research contributes to the adoption and information privacy research in the IS field. A number of opportunities exist for further research. Some of these relate directly to overcoming the limitations of this study. First, in our experimental design, we adopted a narrow focus so as to achieve a high degree of control over extraneous variables. There are other negative aspects such as location data quality and service dependability that may affect LBA adoption, which could also be examined in future research. Second, actual adoption behavior was not measured because the objective of this study was to predict the LBA adoption among potential users who do not yet have credible, meaningful information about, or have affective bonds with, the service providers at the initial adoption/usage stage. Future research could move beyond the domain of the initial adoption/usage stage 
to the domain of continuance/discontinuance of usage whereby consumers already have a longstanding relationship with service providers. Specifically, longitudinal research could be especially useful in investigating how consumers could be motivated to adopt and continue with LBA usage. Third, this study addressed privacy from an institutionbased privacy assurance standpoint (i.e., industry self-regulation and government legislation). Nevertheless, it might be expected that consumers' privacy concerns will be lower when they are empowered with the aid of technologies to exert direct control over personal information in the LBA context (Xu and Teo 2004). Future studies could be carried out to examine the effects of device-based privacy enhancing features (Anuket 2003) on alleviating mobile consumers' privacy concerns.

From a practical perspective, this study provides several important implications for the various players in the LBA industry: merchants, wireless advertising service/content providers, privacy advocates, and government legislators. Given that the individual's concern for privacy is not absolute, but rather can be traded off against benefits, there exist ample opportunities for merchants and wireless advertising service/content providers to offer LBA in practice. There seems to be some evidence to indicate that consumers place high expectations on the entertainment value of mobile advertisements. Wireless advertising service/content providers should consider the importance of entertainment value when designing the interface of LBA messages. Our findings further suggest that privacy protection is a fundamental concern that must be addressed in the LBA context. Mobile consumers desire the implementation of FIPs through self-regulation or legislation to protect their privacy during and after the process of using LBA.

The advent of mobile and positioning technologies has brought about multifaceted impacts on mobile consumers. It is thus imperative for adoption researchers, managers, and policy makers to be aware of the issues involved. Although this research has provided some preliminary evidence toward enriching our understanding in some of these aspects, much research remains to be done in shaping the development of this emerging arena. It would be a challenge to continue improving the experiment design, which could be a scenario where consumers are really on the move. Field research along the directions of this study could contribute significantly toward fostering the acceptance of L-Commerce.

\section{REFERENCES}

Anderson, J. C. "An Approach for Confirmatory Measurement and Structural Equation Modeling of Organizational Properties," Management Science (33:4), 1987, pp. 525-541.

Anuket, B. User Controlled Privacy Protection in Location-Based Services, Unpublished Master's Thesis, University of Maine, Orono, ME, 2003.

Bagozzi, R. P. Causal Models in Marketing, New York: John Wiley \& Sons, 1980.

Bagozzi, R. P. "Marketing as Exchange," Journal of Marketing (39), October 1975, pp. 32-39.

Bagozzi, R. P., and Fornell, C. "Theoretical Concepts, Measurement, and Meaning," in A Second Generation of Multivariate Analysis ( ${ }^{\text {nd }}$ ed.), C. Fornell (Ed.), Westport, CT: Praeger Publishers, 1982.

Barnes, J. S. "Known by the Network: The Emergence of Location-Based Mobile Commerce," in Advances in Mobile Commerce Technologies, E-P. Lim, and K. Siau (Eds.), Hershey PA: Idea Group Publishing, 2003, pp. 171-189. 
Barwise, P., and Strong, C. "Permission-Based Mobile Advertising," Journal of Interactive Marketing (16:1), Winter 2002, pp. 14-24.

Bauer, R., and Greyser, S. Advertising in America, Cambridge, MA: Harvard University Press, 1968.

Beinat, E. "Privacy and Location-based: Stating the Policies Clearly," Geolnformatics, September 2001 (available online at http://www.geodan.n1/nl/geodan/nieuws/pdf/ GeoInformatics_sept_2001_LBSandPrivacy.pdf)

Caudill, M. E., and Murphy, E. P. "Consumer Online Privacy: Legal and Ethical Issues," Journal of Public Policy \& Marketing (19:1), 2000, pp. 7-19.

Chen, Q., and Wells, W. "Attitude Toward the Site," Journal of Advertising Research (39), 1999 pp. 27-37.

Culnan, M. J. "Consumer Awareness of Name Removal Procedures: Implication for Direct Marketing," Journal of Interactive Marketing (9), Spring 1995, pp. 10-19.

Culnan, M. J. "Protecting Privacy Online: Is Self-Regulation Working?," Journal of Public Policy \& Marketing (19:1), 2000, pp. 20-26.

Culnan, M. J., and Armstrong, P. K. "Information Privacy Concerns, Procedural Fairness and Impersonal Trust: An Empirical Investigation," Organization Science (10:1), JanuaryFebraury 1999, pp. 104-115.

Culnan, M. J., and Bies, J. R. "Consumer Privacy: Balancing Economic and Justice Considerations," Journal of Social Issues (59:2), 2003, pp. 323-342.

Ducoffe, R. H. "Advertising Value and Advertising on the Web," Journal of Advertising Research (36), 1996, pp. 21-35.

Eighmey, J. "Profiling User Responses to Commercial Web Sites," Journal of Advertising Research (37:2), 1997, pp. 59-67.

Eighmey, J., and McCord, L. "Adding Value in the Information Age: Uses and Gratifications of Sites on the World Wide Web," Journal of Business Research (41:3), 1998, pp. 187-194.

Fornell, C., and Bookstein, F. L. "Two Structual Equation Models: LISREL and PLS Applied to Customer Exit-Voice Theory,"Journal of Maketing Research (19:11), 1982, pp. 440-452.

Hair, J. F., Anderson, R. E., Tatham, R. L., and Black, W. C. Multivariate Data Analysis with Readings ( $5^{\text {th }}$ ed.), New York: Macmillan, 1998.

Houston, S. F., and Gassenheimer B. J. "Marketing and Exchange," Journal of Marketing (51), 1987, pp. 3-18.

Giaglis, M. G., Kourouthanassis, P., and Tsamakos, A. "Towards a Classification Framework for Mobile Location Services," in Mobile Commerce: Technology, Theory, and Applications, B. E. Mennecke and T. J. Strader (Eds.), Hershey PA: Idea Group Publishing, 2002, pp. 64-81.

Gibbs, J. P. "Deterrence Theory and Research," in Law as a Behavioral Instrument, G. Melton (Ed.), Lincoln, NE: University of Nebraska Press, 1986.

Gidari, A. "No 'L-Commerce ${ }^{\mathrm{SM}}$, Without 'L-Privacy': Fair Location Information Practices for Mobile Commerce," paper presented at L-Commerce 2000-The Location Services \& GPS Technology Summit, Washington, DC, May 2000.

Greenberg, J. "A Taxonomy of Organizational Justice Theories," Academy of Management Review (12:1), 1987, pp. 9-22.

Jarvenpaa, S. L., Tractinsky, N., and Vitale, M. "Consumer Trust in an Internet Store," Information Technology and Management (1:12), 2000, pp. 45-71.

Jöreskog, K. G. "Testing Structural Equation Models," in Testing Structural Equations Models, K. A. Bollen and J. S. Long (Eds.), Newbury Park, CA: Sage Publications, 1993, pp. 294316.

Joseph, B., and Shailesh, J. V. "Concurrent Validity of a Measure of Innovative Cognitive Style," Journal of the Academy of Marketing Science (12), Spring 1984, pp. 159-175. 
Klopfer, P. H., and Rubenstein, D. L "The Concept Privacy and its Biological Basis," Journal of Social Issues (33), 1977, pp. 52-65.

Kölmel, B., and Alexakis, S. "Location Based Advertising," in paper presented at the First International Conference on Mobile Business, Athens, Greece, July 2002.

Laufer, R. S., and Wolfe, M. "Privacy as a Concept and a Social Issue: A Multidimensional Developmental Theory," Journal of Social Issues (33), 1977, pp. 22-41.

Lind, E. A., and Tyler, R. T. The Social Psychology of Procedural Justice, New York: Plenum Press, 1988.

Margulis, T. S. "Privacy as a Social Issue and Behavioral Concept," Journal of Social Issues (59:2), 2003, pp. 243-261.

McQuail, D. Mass Communication Theory: An Introduction ( $1^{\text {st }}$ ed. $)$, London: Sage Publications, 1983.

Nunnally, J. C. Psychometric Theory (2 $2^{\text {nd }}$ ed.), New York: McGraw-Hill, 1978.

Pedersen, E. P. “Adoption of Mobile Internet Services: An Exploratory Study of Mobile Commerce Early Adopters," Journal of Organizational Computing and Electronic Commerce (15:2), 2005 (forthcoming).

Rotenberg, M. "Privacy Protection-A US Perspective," Computer Law \& Security Report (14:1), 1998, pp. 38-40.

Rotzoll, K., Haefner, J., and Sandage, C. Advertising in Contemporary Society: Perspectives Toward Understanding, Cincinnati, OH: South-Western Publishing, 1986.

Shapiro, S. P. "The Social Control of Impersonal Trust," American Journal of Sociology (93:3), 1987, pp. 623-658.

Smith, H. J., Milberg, J. S., and Burke, J. S. "Information Privacy: Measuring Individuals' Concerns About Organizational Practices," MIS Quarterly (20:2), June 1996, pp. 167-196.

Spiro, W. G., and Houghteling, L. J. The Dynamics of Law ( $2^{\text {nd }}$ ed.), New York: Harcourt Brace Jovanovich, 1981, pp. 2-10.

Stone, E. F., and Stone D. L. "Privacy in Organizations: Theoretical Issues, Research Findings, and Protection Mechanisms," Research in Personnel and Human Resources Management (8:3), 1990, pp. 349-411.

Teo, H. H., Wei, K. K., and Benbasat, I. "Predicting Intention to Adopt Interorganizational Linkages: An Institutional Perspective," MIS Quarterly (27:1), March 2003, pp. 1-31.

Tittle, C. R. Sanctions and Social Deviance: The Question of Deterrence, New York: Praeger, 1980.

Ververidis, C., and Polyzos, C. G. "Mobile Marketing Using a Location Based Service," paper presented at the First International Conference on Mobile Business, Athens, Greece, July 2002.

Westin, A. F. Privacy and Freedom, New York: Atheneum, 1967.

$\mathrm{Xu}, \mathrm{H}$., and Teo, H. H. "Alleviating Consumer's Privacy Concern in Location-Based Services: A Psychological Control Perspective," in Proceedings of the $25^{\text {th }}$ International Conference on Information Systems, R. Agarwal, L. Kirsch, and J. I. DeGross (Eds.), Washington, D C, December 2004, pp. 793-806.

$\mathrm{Xu}, \mathrm{H}$., Teo, H. H., and Wang, H. "Foundations of SMS Commerce Success: Lessons from SMS Messaging and Co-opetition," in Proceedings of $36^{\text {th }}$ Hawaii International Conference on System Sciences, R. Sprague (Ed.), Los Alamitos, CA: IEEE Computing Society Press, January 2003, pp. 90-99.

Zeimpekis, V., Giaglis, M. G., and Lekakos, G. "A Taxonomy of Indoor and Outdoor Positioning Techniques for Mobile Location Services," ACM SIGecom Exchanges (3:4), Winter 2003, pp. 19-27. 


\section{ABOUT THE AUTHORS}

Heng $\mathrm{Xu}$ is currently a doctoral candidate in the Department of Information Systems at the National University of Singapore. She received her B.B.A. degree in Information Management and Systems from Shandong University, China, in July 2001. Her research interests include information privacy, technology adoption, and human-computer interaction. Her work has been published in the proceedings of the International Conference on Information Systems, the Hawaii International Conference on System Sciences, and the European Conference on Information Systems, as well as Lecture Notes in Computer Science. She was a recipient of IBM Ph.D. fellowship in 2004. Heng can be reached at xuheng@comp.nus.edu.sg.

Hock-Hai Teo is currently an assistant professor of Information Systems in the Department of Information Systems at the National University of Singapore. He received his Ph.D. (October 1998) in Management of Information Systems from the National University of Singapore. He was a visiting scholar at the Wharton Business School, University of Pennsylvania, from 1999 to 2000. Dr. Teo has published in MIS Quarterly, Journal of Management Information Systems, International Journal of Human-Computer Studies, Journal of Educational Computing Research, Information and Management, Journal of the American Society for Information Science and Technology, Journal of Database Management, and IEEE Transactions on Engineering Management, and has presented at numerous international conferences, including the International Conference on Information Systems. He had also served on the EDIMAN (Electronic Data Interchange for Manufacturing) Standards Working Committee (1995-96) and had conducted executive seminars for Haw Par Group, Singapore Pools, and Ministry of Foreign Affairs (Singapore-Norway Cooperation Program). Dr. Teo is also currently serving as a Director of Mozat Pte Ltd. Dr. Teo can be reached at teohh@comp.nus.edu.sg. 


\section{Appendix A: Descriptive Statistics of Variables}

\begin{tabular}{|c|c|c|}
\hline $\begin{array}{l}\text { Study Vamiales } \\
\end{array}$ & Meai & $S D$ \\
\hline \multicolumn{3}{|l|}{ Theoretical Constructs } \\
\hline Perceived Benefit-Entertainment (ENT) & 5.33 & 0.91 \\
\hline Perceived Benefit-Informativeness (INF) & 5.09 & 0.70 \\
\hline Perceived Risk (RISK) & 4.53 & 1.56 \\
\hline Intention to Use LBA (INT) & 4.47 & 0.87 \\
\hline \multicolumn{3}{|l|}{ Control Constructs } \\
\hline Prior Experience of Using Mobile Applications (PEXP) & 4.64 & 1.56 \\
\hline Innovativeness (INNV) & 5.20 & 1.01 \\
\hline Previous Privacy Experience (PPRV) & 1.30 & 0.65 \\
\hline
\end{tabular}

\section{Appendix B: Intercorrelations among Study Variables}

\begin{tabular}{|c|c|c|c|c|c|c|c|c|}
\hline Construct & BEN & RISK & INT & PEXP & INNV & PPRV & SREG & LEGI \\
\hline BEN & 1.000 & & & & & & & \\
\hline RISK & -0.299 & 000 & & & & & & \\
\hline INT & 0.329 & -0.177 & 1000 & & & & & \\
\hline PEXP & 0.101 & -0.095 & 0.134 & 100 & & & & \\
\hline INNV & 0.097 & -0.125 & 0.317 & 0.157 & 1.000 & & & \\
\hline /PPRV & -0.052 & 0.248 & -0.021 & 0.069 & -0.407 & 1.000 & & \\
\hline SREG & 0.223 & -0.165 & 0.158 & 0.167 & -0.146 & 0.061 & 1.000 & \\
\hline LEGI & 0.011 & -0.306 & 0.145 & 0.023 & -0.050 & -0.113 & 0.167 & 1000 \\
\hline
\end{tabular}




\section{Appendix C: Psychometric Properties of the Measurement Model}

\begin{tabular}{|c|c|c|c|c|c|}
\hline 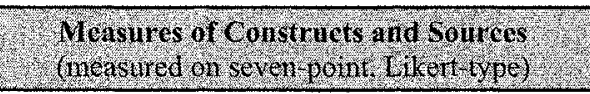 & $(3)^{2}$ & $\log (2)$ & $\mathrm{Cl}^{2}$ & $\mathrm{ar}$ & $x^{2}+x^{2}$ \\
\hline $\begin{array}{l}\text { Entertainment: (Chen and Wells 1999; Ducoffe } \\
\text { 1996) } \\
\text { The location-based advertising is... } \\
\text { entertaining (ENT1). } \\
\text { enjoyable (ENT2). } \\
\text { fun to use (ENT3). } \\
\text { cool (ENT4). } \\
\text { exciting (ENT5). }\end{array}$ & $\begin{array}{l}0.72 \\
0.88 \\
0.91 \\
0.88 \\
0.93\end{array}$ & $\begin{array}{r}7.49 \\
10.04 \\
10.63 \\
9.99 \\
11.11\end{array}$ & 0.937 & 0.961 & 0.810 \\
\hline $\begin{array}{l}\text { Informativeness: (Chen and Wells 1999; Ducoffe } \\
\text { 1996) } \\
\text { The location-based advertising... } \\
\text { is a good source of product information } \\
\text { (INF1). } \\
\text { supplies relevant product information (INF2). } \\
\text { is a good source of up-to-date product } \\
\text { information (INF3). } \\
\text { is a convenient source of product information } \\
\text { (INF4). }\end{array}$ & $\begin{array}{l}0.76 \\
0.68 \\
0.71 \\
0.73\end{array}$ & $\begin{array}{l}7.60 \\
6.57 \\
6.88 \\
7.17\end{array}$ & 0.810 & 0.812 & 0.519 \\
\hline $\begin{array}{l}\text { RISK: (Jarvenpaa et al, } 2000 \text {; Smith et al. 1996) } \\
\text { There would be too mich uncertainty associated } \\
\text { with providing my personal information (e.g., } \\
\text { shopping preferences, mobile phone number, } \\
\text { continuous records of my location information, } \\
\text { and others) to the service provider (RISK1). } \\
\text { There would be a considerable risk if the service } \\
\text { provider shares my personal information with } \\
\text { other companies without notifying me or } \\
\text { getting my authorization (RISK2). } \\
\text { There would be many unexpected problems if the } \\
\text { service provider keeps my personal } \\
\text { information in a non-accurate manner in its } \\
\text { database (RISK3). } \\
\text { There would be high potential for loss if the service } \\
\text { provider does not take measures to prevent } \\
\text { unauthorized access to my personal } \\
\text { information (RISK4). }\end{array}$ & 0.85 & 9.35 & 0.923 & 0.925 & 0.754 \\
\hline $\begin{array}{l}\text { Intent to Use LBA: (Culnan and Armstrong 1999) } \\
\text { How likely would you use such service? (INT1) } \\
\text { How likely would you recommend your friends to } \\
\text { use such service? (INT2) } \\
\text { Would you actively seek out more information about } \\
\text { such service from the service provider's } \\
\text { website? (INT3) }\end{array}$ & $\begin{array}{l}0.86 \\
0.89 \\
0.67\end{array}$ & $\begin{array}{l}9.28 \\
9.74 \\
6.61\end{array}$ & 0.845 & 0.852 & 0.660 \\
\hline
\end{tabular}

(SPE: Standardized Parameter Estimate; CA: Cronbach's Alpha: CR: Composite Reliability; AVE: Average Variance Extracted) 


\section{Appendix D: Goodness of Fit Indices for the Measurement Model}

\begin{tabular}{|c|c|c|c|}
\hline Goodness of fit Indices & Initial Model & Revised Model & Desired Levels \\
\hline$\chi^{2}$ & 191.49 & $\mathbf{1 2 8 . 3 5}$ & Smaller \\
\hline $\mathrm{df}$ & 129 & $\mathbf{9 8}$ & - \\
\hline$\chi^{2} / \mathrm{df}$ & 1.484 & $\mathbf{1 . 3 1 0}$ & $<3.0$ \\
\hline GFI & 0.79 & $\mathbf{0 . 8 5}$ & $>.90$ \\
\hline AGFI & 0.73 & $\mathbf{0 . 7 7}$ & $>.80$ \\
\hline Standardized RMR & 0.066 & $\mathbf{0 . 0 5 9}$ & $<.05$ \\
\hline RMSEA & 0.077 & $\mathbf{0 . 0 6 1}$ & $.05-.08$ \\
\hline NFI & 0.84 & $\mathbf{0 . 9 0}$ & $>.90$ \\
\hline CFI & $\mathbf{0 . 9 4}$ & $\mathbf{0 . 9 8}$ & $>.90$ \\
\hline Number of Latent & & $\mathbf{4}$ & \\
\hline Variables & 4 & $\mathbf{1 6}$ & - \\
\hline Total Number of Items & 18 & & \\
\hline
\end{tabular}

\section{Appendix E: Assessment of Discriminant Validity}

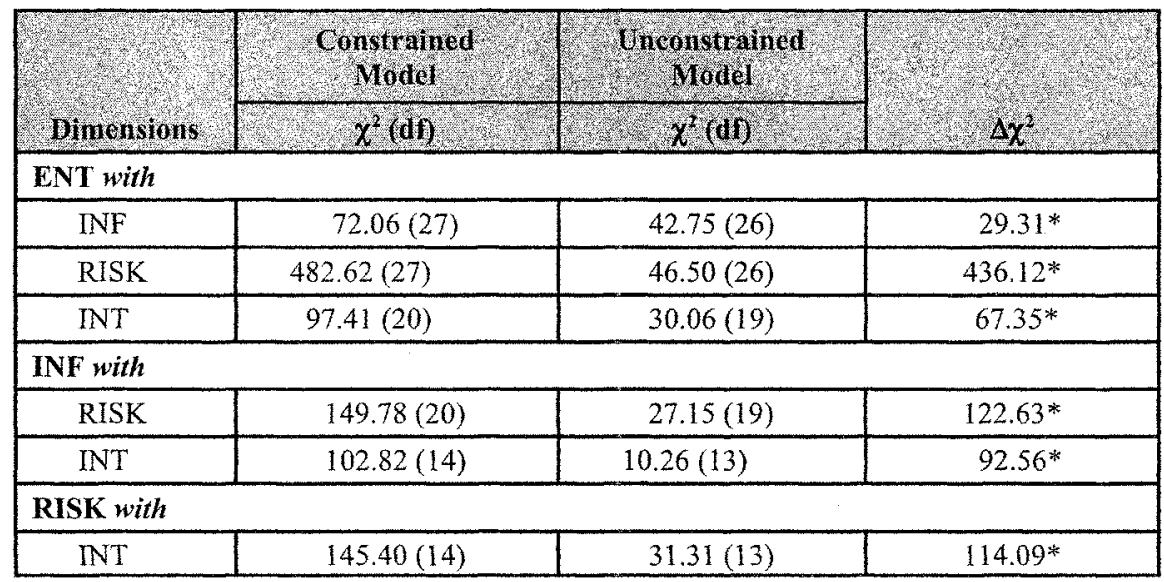

*All differences in $\chi^{2}$ are significant at $p<0.05$. 


\section{Appendix F: Website Screen for M-Coupon Service (with Self-Regulation Manipulation)}

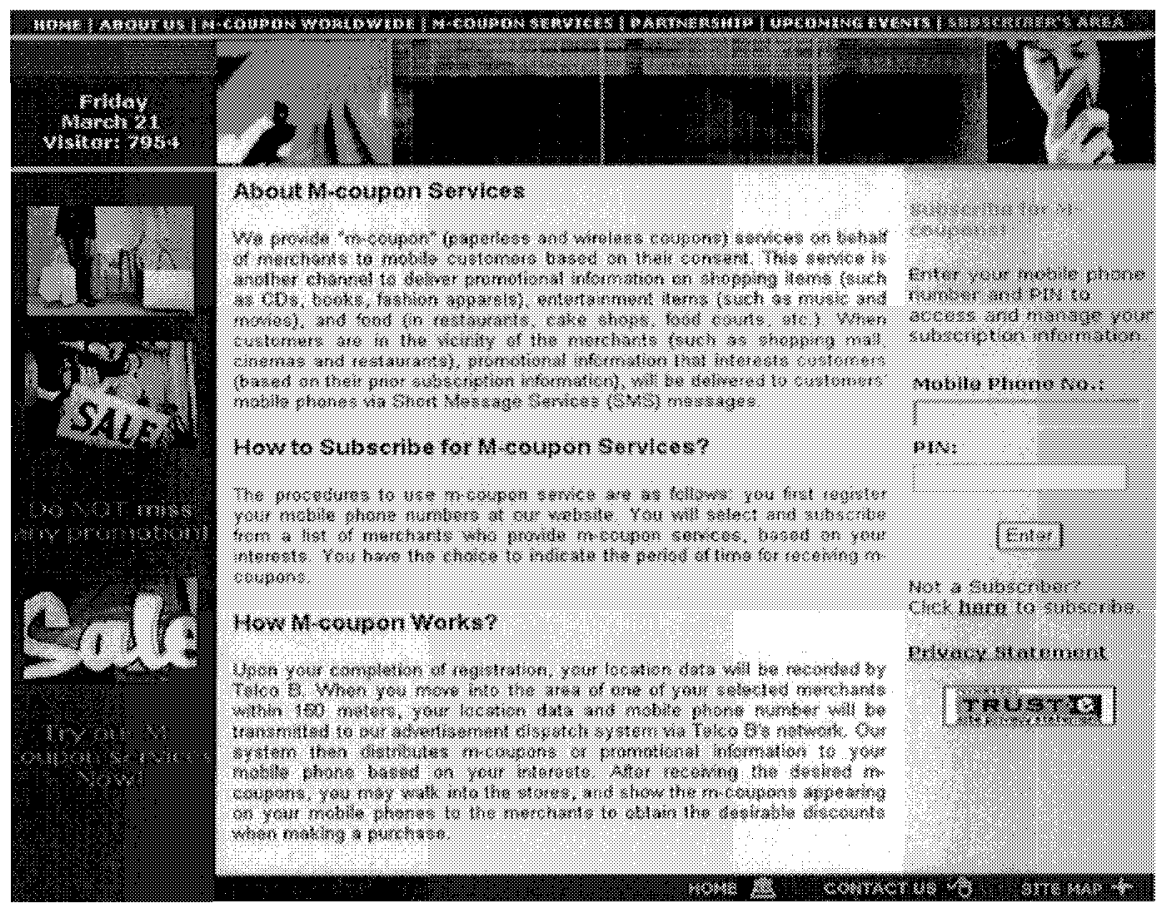

Note: Due to space limitations, we did not provide the screen shot for the M-coupon subscription Web page, the privacy statement page, or other experiment details, which can be requested from the authors. 


\section{Part 3}

Organizational Impact 